\title{
Crystal structure of SARS-CoV-2 main protease provides a basis for design of improved $\alpha$-ketoamide inhibitors
}

\author{
Linlin Zhang', , Daizong Lin ${ }^{1,3}$, Xinyuanyuan Sun ${ }^{1,2}$, Ute Curth ${ }^{4}$, Christian Drosten ${ }^{5}$, \\ Lucie Sauerhering ${ }^{6,7}$, Stephan Becker ${ }^{6,7}$, Katharina $\operatorname{Rox}^{8,9}$, $\operatorname{Rolf~Hilgenfeld~}^{1,2 *}$
}

${ }^{1}$ Institute of Biochemistry, Center for Structural and Cell Biology in Medicine, University of Lübeck, 23562 Lübeck, Germany. ${ }^{2}$ German Center for Infection Research (DZIF), Hamburg-Lübeck-Borstel-Riems Site, University of Lübeck, 23562 Lübeck, Germany. ${ }^{3}$ Changchun Discovery Sciences Ltd., 789 Shunda Road, Changchun, Jilin 130012, China. Institute for Biophysical Chemistry, Hannover Medical School, 30625 Hannover, Germany. ${ }^{5}$ Institute of Virology, Charité Universitätsmedizin Berlin, 10117 Berlin, Germany. Institute of Virology, University of Marburg, 35043 Marburg, Germany. ${ }^{7}$ German Center for Infection Research (DZIF), Marburg-Gießen-Langen Site, University of Marburg, 35043 Marburg, Germany. ${ }^{8}$ Department of Chemical Biology, Helmholtz Center for Infection Research (HZI), Inhoffenstraße 7, 38124 Braunschweig, Germany. ${ }^{9}$ German Center for Infection Research (DZIF), Hannover-Braunschweig Site, Helmholtz Center for Infection Research, 38124 Braunschweig, Germany.

*Corresponding author. Email: rolf.hilgenfeld@uni-luebeck.de

The COVID-19 pandemic caused by SARS-CoV-2 is a global health emergency. An attractive drug target among coronaviruses is the main protease $\left(\mathrm{M}^{\text {pro }}, 3 \mathrm{CL}^{\text {pro }}\right)$, due to its essential role in processing the polyproteins that are translated from the viral RNA. We report the X-ray structures of the unliganded SARS-CoV-2 $\mathrm{M}^{\text {pro }}$ and its complex with an $\alpha$-ketoamide inhibitor. This was derived from a previously designed inhibitor but with the P3-P2 amide bond incorporated into a pyridone ring to enhance the half-life of the compound in plasma. Based on the structure, we developed the lead compound into a potent inhibitor of the SARS-CoV-2 $\mathrm{M}^{\text {pro }}$. The pharmacokinetic characterization of the optimized inhibitor reveals a pronounced lung tropism and suitability for administration by the inhalative route.

In December 2019, a new coronavirus caused an outbreak of pulmonary disease in the city of Wuhan, the capital of $\mathrm{Hu}-$ bei province in China, and has since spread globally $(1,2)$. The virus has been named SARS-CoV-2 (3), because the RNA genome is about $82 \%$ identical to the SARS coronavirus (SARS-CoV); both viruses belong to clade $\mathrm{b}$ of the genus Betacoronavirus $(1,2)$. The disease caused by SARS-CoV-2 is called COVID-19. Whereas at the beginning of the outbreak, cases were connected to the Huanan seafood and animal market in Wuhan, efficient human-to-human transmission led to exponential growth in the number of cases. On March 11, the World Health Organization (WHO) declared the outbreak a pandemic. As of March 15, there are $>170,000$ cumulative cases globally, with a $\sim 3.7 \%$ case-fatality rate .

One of the best characterized drug targets among coronaviruses is the main protease $\left(\mathrm{M}^{\text {pro }}\right.$, also called $\left.3 \mathrm{CL}^{\text {pro }}\right)(4)$. Along with the papain-like protease(s), this enzyme is essential for processing the polyproteins that are translated from the viral RNA (5). The $\mathrm{M}^{\text {pro }}$ operates at no less than 11 cleavage sites on the large polyprotein lab (replicase 1ab, 790 $\mathrm{kDa}$; the recognition sequence at most sites is LeuGln $\downarrow$ (Ser,Ala,Gly) ( $\downarrow$ marks the cleavage site). Inhibiting the activity of this enzyme would block viral replication. Since no human proteases with a similar cleavage specificity are known, inhibitors are unlikely to be toxic.

Previously, we designed and synthesized peptidomimetic $\alpha$-ketoamides as broad-spectrum inhibitors of the main proteases of betacoronaviruses and alphacoronaviruses as well as the $3 \mathrm{C}$ proteases of enteroviruses (6). The best of these compounds (11r; Fig. 1) showed an $\mathrm{EC}_{50}$ of 400 picomolar against MERS-CoV in Huh7 cells as well as low micromolar $\mathrm{EC}_{50}$ values against SARS-CoV and a whole range of enteroviruses in various cell lines, although the antiviral activity seemed to depend to a great extent on the cell type used in the experiments (6). In order to improve the half-life of the compound in plasma, we modified $11 \mathbf{r}$ by hiding the P3 - P2 amide bond within a pyridone ring (Fig. 1 , green circles), in the expectation that this might prevent cellular proteases from accessing this bond and cleaving it. Further, to increase the solubility of the compound in plasma and to reduce its binding to plasma proteins, we replaced the hydrophobic cinnamoyl moiety by the somewhat less hydrophobic Boc group (Fig. 1, red circles) to give 13a (see scheme S1 for synthesis).

In order to examine whether the introduced pyridone ring is compatible with the three-dimensional structure of 
the target, we determined the crystal structure, at $1.75 \AA$ resolution, of the $\mathrm{M}^{\text {pro }}$ of SARS-CoV-2 (Fig. 2). The threedimensional structure is highly similar to that of the SARS$\mathrm{CoV} \mathrm{M}^{\text {pro }}$, as expected from the $96 \%$ sequence identity (see fig. S7); the r.m.s. deviation between the two free-enzyme structures is $0.53 \AA$ for all $\mathrm{C} \alpha$ positions (comparison between SARS-CoV-2 $\mathrm{M}^{\text {pro }}$ structure and SARS-CoV $\mathrm{M}^{\text {pro }}$, PDB entry $2 \mathrm{BX} 4(7))$. The chymotrypsin- and picornavirus $3 \mathrm{C}$ protease-like domains I and II (residues 10-99 and 100-182, respectively) are six-stranded antiparallel $\beta$-barrels that harbor the substrate-binding site between them. Domain III (residues 198-303), a globular cluster of five helices, is involved in regulating dimerization of the $\mathrm{M}^{\text {pro }}$, mainly through a salt-bridge interaction between $\mathrm{Glu}^{290}$ of one protomer and $\mathrm{Arg}^{4}$ of the other (8). The tight dimer formed by SARS-CoV-2 $\mathrm{M}^{\text {pro }}$ has a contact interface, predominantly between domain II of molecule $\mathrm{A}$ and the $\mathrm{NH}_{2}$-terminal residues ("N-finger") of molecule B, of $\sim 1394 \AA^{2}$, with the two molecules oriented perpendicular to one another (Fig. 2). Dimerization of the enzyme is necessary for catalytic activity, because the N-finger of each of the two protomers interacts with $\mathrm{Glu}^{166}$ of the other protomer and thereby helps shape the S1 pocket of the substrate-binding site (9). To reach this interaction site, the $\mathrm{N}$-finger is squeezed in between domains II and III of the parent monomer and domain II of the other monomer. Interestingly, in the SARS$\mathrm{CoV}$ but not in the SARS-CoV-2 $\mathrm{M}^{\text {pro }}$ dimer, there is a polar interaction between the two domains III involving a 2.60- $\AA$ hydrogen bond between the side-chain hydroxyl groups of residue $\mathrm{Thr}^{285}$ of each protomer, and supported by a hydrophobic contact between the side-chain of $\mathrm{Ile}^{286}$ and $\mathrm{Thr}^{285}$ $\mathrm{C} \gamma 2$. In SARS-CoV-2, the threonine is replaced by alanine (indicated by the black sphere in Fig. 2), and the isoleucine by leucine (see fig. S7). It has previously been shown that replacing $\mathrm{Ser}^{284}$, $\mathrm{Thr}^{285}$, and $\mathrm{Ile}^{286}$ by alanine residues in SARS-CoV M $M^{\text {pro }}$ leads to a 3.6-fold enhancement of the catalytic activity of the protease, concomitant with a slightly closer packing of the two domains III of the dimer against one another (10). This was accompanied by changes in enzyme dynamics that transmit the effect of the mutation to the catalytic center. Indeed, the $\mathrm{Thr}^{285} \mathrm{Ala}$ replacement observed in the SARS-CoV-2 $\mathrm{M}^{\text {pro }}$ also allows the two domains III to approach each other a little closer (the distance between the $\mathrm{C} \alpha$ atoms of residues 285 in molecules $\mathrm{A}$ and $\mathrm{B}$ is 6.77 $\AA$ in SARS-CoV $\mathrm{M}^{\text {pro }}$ and 5.21 $\AA$ in SARS-CoV-2 $\mathrm{M}^{\text {pro }}$ and the distance between the centers of mass of the two domains III shrinks from $33.4 \AA$ to $32.1 \AA$ ). However, the catalytic efficiency of SARS-CoV-2 $\mathrm{M}^{\text {pro }}$ is only slightly higher, if at all $\left(k_{\text {cat }} / K_{\mathrm{m}}=3426.1 \pm 416.9 \mathrm{~s}^{-1} \mathrm{M}^{-1}\right)$ than that of SARS-CoV $\mathrm{M}^{\text {pro }}\left(k_{\text {cat }} / K_{\mathrm{m}}=3011.3 \pm 294.6 \mathrm{~s}^{-1} \mathrm{M}^{-1}\right)$. Further, the estimated $K_{\mathrm{d}}$ of dimer dissociation is the same $(\sim 2.5 \mu \mathrm{M})$ for the two enzymes, as determined by analytical ultracentrifugation (fig. S8).

We used this crystal structure to dock the $\alpha$-ketoamide 13a; this suggested that the pyridone ring might have some steric clash with the side-chain of Gln189. However, in our previous work (6), we had found Gln189 to be quite flexible and therefore we went ahead with $13 \mathrm{a}$ as a lead. The plasma half-life of this compound in mice was increased $\sim 3$-fold compared to $\mathbf{1 1 r}$ (from 0.3 hours to 1.0 hours), the in-vitro kinetic plasma solubility was improved by a factor of $\sim 19$ (from $6 \mu \mathrm{M}$ for $11 \mathbf{r}$ to $112 \mu \mathrm{M}$ for 13a) and the thermodynamic solubility by a factor of $\sim 13$ (from $41 \mu \mathrm{M}$ to $530 \mu \mathrm{M}$ ). Binding to mouse plasma protein was reduced from $99 \%$ to 97\% (many drugs have plasma protein binding of $>90 \%$; (11)). However, compared to $\mathbf{1 1 r}\left(\mathrm{IC}_{50}=0.18 \pm 0.02 \mu \mathrm{M}\right)$, the structural modification led to some loss of inhibitory activity against the main protease of SARS-CoV-2 $\left(\mathrm{IC}_{50}=2.39 \pm\right.$ $0.63 \mu \mathrm{M})$ as well as the $3 \mathrm{C}$ proteases $\left(3 \mathrm{C}^{\text {pro }}\right)$ of enteroviruses. 11r was designed for broad-spectrum activity, with the P2 cyclohexyl moiety intended to fill a pocket in the enterovirus $3 \mathrm{C}^{\text {pro }}$. The $\mathrm{S} 2$ pocket of the betacoronavirus $\mathrm{M}^{\text {pro }}$ (see Fig. 3) features substantial plasticity enabling it to adapt to the shape of smaller inhibitor moieties (6). To enhance the antiviral activity against betacoronaviruses of clade $b$ (SARSCoV-2 and SARS-CoV), we sacrificed the goal of broadspectrum activity and replaced the P2 cyclohexyl moiety of $\mathbf{1 3 a}$ by the smaller cyclopropyl in 13b (Fig. 1, blue circles). Here we present X-ray crystal structures in two different crystal forms, at 1.95 and $2.20 \AA$ resolution, of the complex between $\alpha$-ketoamide $\mathbf{1 3 b}$ and the $\mathrm{M}^{\text {pro }}$ of SARS-CoV-2 (Fig. 3 ). One structure is in space group $C 2$, where both protomers of the $\mathrm{M}^{\text {pro }}$ dimer are bound by crystal symmetry to have identical conformations, the other is in space group $P 2_{1} 2_{1} 2_{1}$, where the two protomers are independent of each other and free to adopt different conformations. Indeed, we find that in the latter crystal structure, the key residue Glu $^{166}$ adopts an inactive conformation in protomer B (as evidenced by its distance from $\mathrm{His}^{172}$ and the lack of $\mathrm{H}$ bonding interaction with the P1 moiety of the inhibitor), even though compound $\mathbf{1 3 b}$ is bound in the same mode as in molecule A. This phenomenon has also been observed with the SARS-CoV M $\mathrm{M}^{\text {pro }}$ (12) and is consistent with the halfsite activity described for this enzyme (13). In all copies of the inhibited SARS-CoV-2 $\mathrm{M}^{\text {pro }}$, the inhibitor binds to the shallow substrate-binding site at the surface of each protomer, between domains I and II (Fig. 3).

Through the nucleophilic attack of the catalytic Cys ${ }^{145}$ onto the $\alpha$-keto group of the inhibitor, a thiohemiketal is formed in a reversible reaction. This is clearly reflected in the electron density (Fig. 3 inset); the stereochemistry of this chiral moiety is $S$ in all copies of compound $\mathbf{1 3 b}$ in these structures. The oxyanion (or hydroxyl) group of this thiohemiketal is stabilized by a hydrogen bond from $\mathrm{His}^{41}$, 
whereas the amide oxygen of $\mathbf{1 3 b}$ accepts a hydrogen bond from the main-chain amides of $\mathrm{Gly}^{143}$, $\mathrm{Cys}^{145}$, and partly Ser ${ }^{144}$, which form the canonical "oxyanion hole" of the cysteine protease. It is an advantage of the $\alpha$-ketoamides that their warhead can interact with the catalytic center of the target proteases through two hydrogen bonding interactions (6), rather than only one as with other warheads such as aldehydes (14) or Michael acceptors (15).

The P1 $\gamma$-lactam moiety, designed as a glutamine surrogate $(15,16)$, is deeply embedded in the S1 pocket of the protease, where the lactam nitrogen donates a three-center (bifurcated) hydrogen bond to the main-chain oxygen of $\mathrm{Phe}^{140}(3.20 / 3.10 / 3.28 \AA$; values for the structure in space group $C 2 /$ space group $P 2_{1} 2_{1} 2_{1}$ molecule $\mathrm{A} /$ space group $P 2_{1} 2_{1} 2_{1}$ molecule $B$ ) and to the $\mathrm{Glu}^{166}$ carboxylate $(3.35 / 3.33 /(3.55) \AA)$, and the carbonyl oxygen accepts a $2.57 / 2.51 / 2.81-\AA$ H-bond from the imidazole of $\mathrm{His}^{163}$. The P2 cyclopropyl methyl moiety fits snugly into the S2 subsite, which has shrunk by $28 \AA^{3}$ compared to the complex between compound 13a with P2 = cyclohexyl methyl and the SARS-CoV $\mathrm{M}^{\text {pro }}$ (17). The pyridone in the P3 - P2 position of the inhibitor occupies the space normally filled by the substrate's main chain, its carbonyl oxygen accepts a 2.89/2.99/3.00- $\AA$ hydrogen bond from the main-chain amide of residue $\mathrm{Glu}^{166}$. Further, the P3 amide donates a 2.83/2.96/2.87- $\AA$ H-bond to the main-chain oxygen of $\mathrm{Glu}^{166}$. Embedded within the pyridone, the P2 nitrogen can no longer donate a hydrogen bond to the protein (the $\mathrm{H}$-bond prevented from forming would connect the P2 nitrogen and the side-chain oxygen of Gln189; these two atoms are highlighted in fig. S8). However, our previous crystal structures showed that the P2 main-chain amide of the linear $\alpha$ ketoamides does not make a hydrogen bond with the protein in all cases, so this interaction does not seem to be critical (6). The protecting Boc group on P3 does not occupy the canonical S4 site of the protease (in contrast to the protecting groups of other inhibitors in complex with the SARS$\mathrm{CoV} \mathrm{M}^{\text {pro }}(18)$ ), but is located near $\operatorname{Pro}^{168}$ (3.81/4.17/3.65 $\AA$; Fig. 3); due to this interaction, the latter residue moves outward by more than $2 \AA$ (compared to the structure of the free enzyme). This contact explains why removing the Boc group as in compound 14b (Fig. 1, purple circles) weakens the inhibitory potency of this compound by a factor of about 2. Interestingly, there is a space between the pyridone ring of $\mathbf{1 3 b}$, the main chain of residue $\mathrm{Thr}^{190}$, and the side-chain of $\mathrm{Gln}^{189}$ (smallest distance: $3.6 \AA$ ) which is filled by a DMSO molecule in the $C 2$ crystal structure and a water molecule in the $P 2_{1} 2_{1} 2_{1}$ structure. This suggests that P3 moieties more bulky than pyridone may be accepted here.

Compound 13b inhibits the purified recombinant SARSCoV-2 $\mathrm{M}^{\text {pro }}$ with $\mathrm{IC}_{50}=0.67 \pm 0.18 \mu \mathrm{M}$. The corresponding $\mathrm{IC}_{50}$ values for inhibition of the SARS-CoV $\mathrm{M}^{\text {pro }}$ and the
MERS-CoV $\mathrm{M}^{\text {pro }}$ are $0.90 \pm 0.29 \mu \mathrm{M}$ and $0.58 \pm 0.22 \mu \mathrm{M}$, respectively. In a SARS-CoV replicon (19), RNA replication is inhibited with $\mathrm{EC}_{50}=1.75 \pm 0.25 \mu \mathrm{M}$. In human Calu3 cells infected with the novel coronavirus, SARS-CoV-2, an $\mathrm{EC}_{50}$ of $4-5 \mu \mathrm{M}$ is observed, whereas compound 14b lacking the Boc group is almost inactive (Fig. 4). This suggests that the hydrophobic and bulky Boc group is necessary to cross the cellular membrane and that an even more hydrophobic moiety might be advantageous here, although this may again lead to increased plasma protein binding as observed for the cinnamoyl-containing $\mathbf{1 1 r}$.

To assess the absorption - distribution - metabolism excretion (ADME) properties of the pyridone-containing $\alpha$ ketoamides, we first investigated compound 13a. Metabolic stability in mouse and human microsomes was good, with intrinsic clearance rates $\mathrm{Cl}_{\text {int_mouse }}=32.0 \mu \mathrm{L} / \mathrm{min} / \mathrm{mg}$ protein and $\mathrm{Cl}_{\text {int_human }}=21.0 \mu \mathrm{L} / \mathrm{min} / \mathrm{mg}$ protein. This means that after $30 \mathrm{~min}$, around $80 \%$ for mouse and $60 \%$ for humans, respectively, of residual compound remained metabolically stable. Pharmacokinetic studies in CD-1 mice using the subcutaneous route at $20 \mathrm{mg} / \mathrm{kg}$ showed that $13 a$ stayed in plasma for up to only 4 hours, but was excreted via urine for up to 24 hours. The $\mathrm{C}_{\max }$ was determined at $334.5 \mathrm{ng} / \mathrm{mL}$ and the mean residence time was about 1.6 hours. Although 13a seemed to be cleared very rapidly from plasma, it was found at 24 hours at $135 \mathrm{ng} / \mathrm{g}$ tissue in the lung and at 52.7 $\mathrm{ng} / \mathrm{mL}$ in broncheo-alveolar lavage fluid (BALF) suggesting that it was mainly distributed to tissue. Next, we investigated 13b for its pharmacokinetic properties in CD-1 mice using the subcutaneous route as well, but at $3 \mathrm{mg} / \mathrm{kg}$. ADME parameters of $\mathbf{1 3 b}$ were similar to $\mathbf{1 3 a}$; in addition, the binding to human plasma proteins was found to be $90 \%$. The $\mathrm{C}_{\max }$ of $13 \mathbf{b}$ was determined at $126.2 \mathrm{ng} / \mathrm{mL}$. This is around $37 \%$ of the $\mathrm{C}_{\max }$ detected for $\mathbf{1 3 a}$, although $\mathbf{1 3 b}$ dosage was approximately 7 -times lower. The mean residence time for $\mathbf{1 3 b}$ was extended to 2.7 hours and the plasma halflife in mice was 1.8 hours. In addition, 13b showed a less rapid clearance compared to $\mathbf{1 3 a}$ (table S3). During the pharmacokinetic study with $\mathbf{1 3 b}$, we monitored its lung tissue levels. After 4 hours, around $13 \mathrm{ng} / \mathrm{g} \mathbf{1 3 b}$ were still found in lung tissue. This lung tropism of $\mathbf{1 3 a}$ and $\mathbf{1 3 b}$ is beneficial given that COVID-19 affects the lungs. In addition to subcutaneous administration, 13b was nebulized using an inhalation device at $3 \mathrm{mg} / \mathrm{kg}$. After 24 hours, $33 \mathrm{ng} / \mathrm{g} \mathbf{1 3 b}$ were found in lung tissue. Inhalation was tolerated well and mice did not show any adverse effects, suggesting that this way, direct administration of the compound to the lungs would be possible. Given these favorable pharmacokinetic results, our study provides a useful framework for development of the pyridone-containing inhibitors toward anticoronaviral drugs. 


\section{REFERENCES AND NOTES}

1. P. Zhou, X.-L. Yang, X.-G. Wang, B. Hu, L. Zhang, W. Zhang, H.-R. Si, Y. Zhu, B. Li, C.-L. Huang, H.-D. Chen, J. Chen, Y. Luo, H. Guo, R.-D. Jiang, M.-Q. Liu, Y. Chen, X.-R. Shen, X. Wang, X.-S. Zheng, K. Zhao, Q.-J. Chen, F. Deng, L.-L. Liu, B. Yan, F.-X. Zhan, Y.-Y. Wang, G.-F. Xiao, Z.-L. Shi, A pneumonia outbreak associated with a new coronavirus of probable bat origin. Nature 579, 270-273 (2020). doi:10.1038/s41586-020-2012-7 Medline

2. F. Wu, S. Zhao, B. Yu, Y.-M. Chen, W. Wang, Z.-G. Song, Y. Hu, Z.-W. Tao, J.-H. Tian, Y.-Y. Pei, M.-L. Yuan, Y.-L. Zhang, F.-H. Dai, Y. Liu, Q.-M. Wang, J.-J. Zheng, L. Xu, E. C. Holmes, Y.-Z. Zhang, A new coronavirus associated with human respiratory disease in China. Nature 579, 265-269 (2020). doi:10.1038/s41586-020-20083 Medline

3. A. E. Gorbalenya, S. C. Baker, R. S. Baric, R. J. de Groot, C. Drosten, A. A. Gulyaeva, B. L. Haagmans, C. Lauber, A. M. Leontovich, B. W. Neuman, D. Penzar, S. Perlman, L. L. M. Poon, D. Samborskiy, I. A. Sidorov, I. Sola, J. Ziebuhr, Severe acute respiratory syndrome-related coronavirus: The species and its viruses - a statement of the Coronavirus Study Group. Nat. Microbiol. (2020). 10.1038/s41564-020-0695-z

4. K. Anand, J. Ziebuhr, P. Wadhwani, J. R. Mesters, R. Hilgenfeld, Coronavirus main proteinase $\left(3 \mathrm{CL}^{\text {pro }}\right)$ structure: Basis for design of anti-SARS drugs. Science 300 , 1763-1767 (2003). doi:10.1126/science.1085658 Medline

5. R. Hilgenfeld, From SARS to MERS: Crystallographic studies on coronaviral proteases enable antiviral drug design. FEBS J. 281, 4085-4096 (2014). doi:10.1111/febs.12936 Medline

6. L. Zhang, D. Lin, Y. Kusov, Y. Nian, Q. Ma, J. Wang, A. von Brunn, P. Leyssen, K. Lanko, J. Neyts, A. de Wilde, E. J. Snijder, H. Liu, R. Hilgenfeld, $\alpha$-Ketoamides as broad-spectrum inhibitors of coronavirus and enterovirus replication: Structurebased design, synthesis, and activity assessment. J. Med. Chem. acs.jmedchem.9b01828 (2020). doi:10.1021/acs.jmedchem.9b01828 Medline

7. J. Tan, K. H. G. Verschueren, K. Anand, J. Shen, M. Yang, Y. Xu, Z. Rao, J. Bigalke, B. Heisen, J. R. Mesters, K. Chen, X. Shen, H. Jiang, R. Hilgenfeld, pH-dependent conformational flexibility of the SARS-CoV main proteinase $\left(\mathrm{M}^{\text {pro }}\right)$ dimer: Molecular dynamics simulations and multiple X-ray structure analyses. J. Mol. Biol. 354, 25-40 (2005). doi:10.1016/j.jmb.2005.09.012 Medline

8. J. Shi, J. Song, The catalysis of the SARS 3C-like protease is under extensive regulation by its extra domain. FEBS J. 273, 1035-1045 (2006). doi:10.1111/i.1742-4658.2006.05130.x Medline

9. K. Anand, G. J. Palm, J. R. Mesters, S. G. Siddell, J. Ziebuhr, R. Hilgenfeld, Structure of coronavirus main proteinase reveals combination of a chymotrypsin fold with an extra alpha-helical domain. EMBO J. 21, 3213-3224 (2002). doi:10.1093/emboj/cdf327 Medline

10. L. Lim, J. Shi, Y. Mu, J. Song, Dynamically-driven enhancement of the catalytic machinery of the SARS 3C-like protease by the S284-T285-I286/A mutations on the extra domain. PLOS ONE 9, e101941 (2014). doi:10.1371/journal.pone.0101941 Medline

11. N. A. Kratochwil, W. Huber, F. Müller, M. Kansy, P. R. Gerber, Predicting plasma protein binding of drugs: A new approach. Biochem. Pharmacol. 64, 1355-1374 (2002). doi:10.1016/S0006-2952(02)01074-2 Medline

12. H. Yang, M. Yang, Y. Ding, Y. Liu, Z. Lou, Z. Zhou, L. Sun, L. Mo, S. Ye, H. Pang, G. F. Gao, K. Anand, M. Bartlam, R. Hilgenfeld, Z. Rao, The crystal structures of severe acute respiratory syndrome virus main protease and its complex with an inhibitor. Proc. Natl. Acad. Sci. U.S.A. 100, 13190-13195 (2003). doi:10.1073/pnas.1835675100 Medline

13. H. Chen, P. Wei, C. Huang, L. Tan, Y. Liu, L. Lai, Only one protomer is active in the dimer of SARS 3C-like proteinase. J. Biol. Chem. 281, 13894-13898 (2006). doi:10.1074/jbc.M510745200 Medline

14. L. Zhu, S. George, M. F. Schmidt, S. I. Al-Gharabli, J. Rademann, R. Hilgenfeld, Peptide aldehyde inhibitors challenge the substrate specificity of the SARScoronavirus main protease. Antiviral Res. 92, 204-212 (2011). doi:10.1016/i.antiviral.2011.08.001 Medline
15. J. Tan, S. George, Y. Kusov, M. Perbandt, S. Anemüller, J. R. Mesters, H. Norder, B. Coutard, C. Lacroix, P. Leyssen, J. Neyts, R. Hilgenfeld, 3C protease of enterovirus 68: Structure-based design of Michael acceptor inhibitors and their broad-spectrum antiviral effects against picornaviruses. J. Virol. 87, 4339-4351 (2013). doi:10.1128/JVI.01123-12 Medline

16. P. S. Dragovich, R. Zhou, D. J. Skalitzky, S. A. Fuhrman, A. K. Patick, C. E. Ford, J. W. Meador 3rd, S. T. Worland, Solid-phase synthesis of irreversible human rhinovirus $3 \mathrm{C}$ protease inhibitors. Part 1: Optimization of tripeptides incorporating N-terminal amides. Bioorg. Med. Chem. 7, 589-598 (1999). doi:10.1016/S0968-0896(99)00005-X Medline

17. L. Zhang, D. Lin, R. Hilgenfeld, Crystal structure of the complex resulting from the reaction between the SARS-CoV main protease and tert-butyl (1-((S)-3cyclohexyl-1-(((S)-4-(cyclopropylamino)-3,4-dioxo-1-((S)-2-oxopyrrolidin-3yl)butan-2-yl) amino)-1-oxopropan-2-yl)-2-oxo-1,2-dihydropyridin-3yl)carbamate, PDB ID 6Y7M (2020). doi:10.2210/pdb6Y7M/pdb

18. L. Zhu, R. Hilgenfeld, Crystal structure of SARS coronavirus main protease complexed with an alpha, beta-unsaturated ethyl ester inhibitor SG85, PDB ID 3TNT (2012). doi:10.2210/pdb3TNT/pdb

19. Y. Kusov, J. Tan, E. Alvarez, L. Enjuanes, R. Hilgenfeld, A G-quadruplex-binding macrodomain within the "SARS-unique domain" is essential for the activity of the SARS-coronavirus replication-transcription complex. Virology 484, 313-322 (2015). doi:10.1016/j,virol.2015.06.016 Medline

20. X. Xue, H. Yang, W. Shen, Q. Zhao, J. Li, K. Yang, C. Chen, Y. Jin, M. Bartlam, Z. Rao, Production of authentic SARS-CoV Mpro with enhanced activity: Application as a novel tag-cleavage endopeptidase for protein overproduction. J. Mol. Biol. 366, 965-975 (2007). doi:10.1016/j.jmb.2006.11.073 Medline

21. U. Mueller, N. Darowski, M. R. Fuchs, R. Förster, M. Hellmig, K. S. Paithankar, S. Pühringer, M. Steffien, G. Zocher, M. S. Weiss, Facilities for macromolecular crystallography at the Helmholtz-Zentrum Berlin. J. Synchrotron Radiat. 19, 442-449 (2012). doi:10.1107/S0909049512006395 Medline

22. M. Krug, M. S. Weiss, U. Heinemann, U. Mueller, XDSAPP: A graphical user interface for the convenient processing of diffraction data using XDS. J. Appl. Crystallogr. 45, 568-572 (2012). doi:10.1107/S0021889812011715

23. P. Evans, Scaling and assessment of data quality. Acta Crystallogr. D 62, 72-82 (2006). doi:10.1107/S0907444905036693 Medline

24. P. R. Evans, An introduction to data reduction: Space-group determination, scaling and intensity statistics. Acta Crystallogr. D 67, 282-292 (2011). doi:10.1107/S090744491003982X Medline

25. M. D. Winn, C. C. Ballard, K. D. Cowtan, E. J. Dodson, P. Emsley, P. R. Evans, R. M. Keegan, E. B. Krissinel, A. G. Leslie, A. McCoy, S. J. McNicholas, G. N. Murshudov, N. S. Pannu, E. A. Potterton, H. R. Powell, R. J. Read, A. Vagin, K. S. Wilson, Overview of the CCP4 suite and current developments. Acta Crystallogr. D 67, 235-242 (2011). doi:10.1107/S0907444910045749 Medline

26. A. Vagin, A. Teplyakov, Molecular replacement with MOLREP. Acta Crystallogr. D 66, 22-25 (2010). doi:10.1107/S0907444909042589 Medline

27. A. A. Lebedev, P. Young, M. N. Isupov, O. V. Moroz, A. A. Vagin, G. N. Murshudov, JLigand: A graphical tool for the CCP4 template-restraint library. Acta Crystallogr. D 68, 431-440 (2012). doi:10.1107/S090744491200251X Medline

28. P. Emsley, B. Lohkamp, W. G. Scott, K. Cowtan, Features and development of Coot. Acta Crystallogr. D 66, 486-501 (2010). doi:10.1107/S0907444910007493 Medline

29. G. N. Murshudov, P. Skubák, A. A. Lebedev, N. S. Pannu, R. A. Steiner, R. A. Nicholls, M. D. Winn, F. Long, A. A. Vagin, REFMAC5 for the refinement of macromolecular crystal structures. Acta Crystallogr. D 67, 355-367 (2011). doi:10.1107/S0907444911001314 Medline

30. Y. Liu, W. Kati, C. M. Chen, R. Tripathi, A. Molla, W. Kohlbrenner, Use of a fluorescence plate reader for measuring kinetic parameters with inner filter effect correction. Anal. Biochem. 267, 331-335 (1999). doi:10.1006/abio.1998.3014 Medline

31. P. H. Brown, A. Balbo, P. Schuck, Characterizing protein-protein interactions by 
sedimentation velocity analytical ultracentrifugation. Curr. Protoc. Immunol. Chapter 18, Unit 18.15 (2008).

32. P. Schuck, Size-distribution analysis of macromolecules by sedimentation velocity ultracentrifugation and lamm equation modeling. Biophys. J. 78, 16061619 (2000). doi:10.1016/S0006-3495(00)76713-0 Medline

33. M. T. Laue, B. D. Shah, T. M. Rigdeway, S. L. Pelletier, in Analytical Ultracentrifugation in Biochemistry and Polymer Science, S. Harding, A. Rowe, J. Horton, Eds. (Royal Society of Chemistry, 1992), pp. 90-125.

34. E. F. Pettersen, T. D. Goddard, C. C. Huang, G. S. Couch, D. M. Greenblatt, E. C. Meng, T. E. Ferrin, UCSF Chimera-A visualization system for exploratory research and analysis. J. Comput. Chem. 25, 1605-1612 (2004). doi:10.1002/jcc.20084 Medline

35. Q. Tian, N. K. Nayyar, S. Babu, L. Chen, J. Tao, S. Lee, A. Tibbetts, T. Moran, J. Liou, M. Guo, T. P. Kennedy, An efficient synthesis of a key intermediate for the preparation of the rhinovirus protease inhibitor AG7088 via asymmetric dianionic cyanomethylation of N-Boc-L-(+)-glutamic acid dimethyl ester. Tetrahedron Lett. 42, 6807-6809 (2001). doi:10.1016/S0040-4039(01)01416-2

36. V. M. Corman, O. Landt, M. Kaiser, R. Molenkamp, A. Meijer, D. K. W. Chu, T. Bleicker, S. Brünink, J. Schneider, M. L. Schmidt, D. G. J. C. Mulders, B. L. Haagmans, B. van der Veer, S. van den Brink, L. Wijsman, G. Goderski, J. L. Romette, J. Ellis, M. Zambon, M. Peiris, H. Goossens, C. Reusken, M. P. G. Koopmans, C. Drosten, Detection of 2019 novel coronavirus (2019-nCoV) by real-time RT-PCR. Euro Surveill. 25, (2020). doi:10.2807/15607917.ES.2020.25.3.2000045 Medline

37. Y. Zhang, M. Huo, J. Zhou, S. Xie, PKSolver: An add-in program for pharmacokinetic and pharmacodynamic data analysis in Microsoft Excel. Comput. Methods Programs Biomed. 99, 306-314 (2010). doi:10.1016/j.cmpb.2010.01.007 Medline

38. W. C. Hsu, H. C. Chang, C. Y. Chou, P. J. Tsai, P. I. Lin, G. G. Chang, Critical assessment of important regions in the subunit association and catalytic action of the severe acute respiratory syndrome coronavirus main protease. J. Biol. Chem. 280, 22741-22748 (2005). doi:10.1074/jbc.M502556200 Medline

39. C. A. Bräutigam, Calculations and publication-quality illustrations for analytical ultracentrifugation data. Methods Enzymol. 562, 109-133 (2015). doi:10.1016/bs.mie.2015.05.001 Medline

40. M. S. Weiss, R. Hilgenfeld, On the use of the merging $R$ factor as a quality indicator for X-ray data. J. Appl. Crystallogr. 30, 203-205 (1997). doi:10.1107/S0021889897003907

41. P. A. Karplus, K. Diederichs, Linking crystallographic model and data quality. Science 336, 1030-1033 (2012). doi:10.1126/science.1218231 Medline

42. V. B. Chen, W. B. Arendall 3rd, J. J. Headd, D. A. Keedy, R. M. Immormino, G. J. Kapral, L. W. Murray, J. S. Richardson, D. C. Richardson, MolProbity: All-atom structure validation for macromolecular crystallography. Acta Crystallogr. D 66, 12-21 (2010). doi:10.1107/S0907444909042073 Medline

\section{ACKNOWLEDGMENTS}

The authors are grateful to Yuri Kusov and Guido Hansen as well as Aws Aljnabi for determining the inhibitory activities of compounds in a SARS-CoV replicon and against recombinant MERS-CoV Mpro, respectively, and to Thorsten Biet for recording ${ }^{13} \mathrm{C}$ NMR spectra. We thank Andrea Ahlers, Janine Schreiber, and Lidia Litz for excellent technical assistance, Kuilan Chen for continuous organizational support, and the staff at beamline 14.2 of BESSY II, Berlin, Germany, for help with diffraction data collection. Funding: We thank the German Center for Infection Research (DZIF) for financial support (projects TTU01, grant \# 8011801806, and TTU09, grant \# 8004709710). Author contributions: Conceptualization: LLZ, DZL, RH; Investigation: LLZ, DZL, XYYS, UC, LS, SB, KR, RH; Contribution of research materials: CD; Writing - original draft preparation: RH, DZL, KR; Writing - review and editing: LLZ, DZL, UC, LS, KR, RH; Visualization: LLZ, LS; Supervision: RH; Funding acquisition: RH, SB, KR; Competing interests: The University of Lübeck has filed a patent application covering compounds $13 \mathrm{a}$ and $13 \mathrm{~b}$ as well as related compounds with a pyridone structure in the P3 - P2 position, with LLZ, DZL, and RH as inventors.
Data and materials availability: Crystallographic coordinates and structure factors are available from the PDB under accession codes 6Y2E (unliganded $\mathrm{M}^{\text {pro }}$ ), 6Y2F (complex with 13b in space group $C 2$ ), and $6 \mathrm{Y} 2 \mathrm{G}$ (complex with $13 \mathrm{~b}$ in space group $P 22_{2} 2_{1}$ ). The plasmid encoding the SARS-CoV-2 $\mathrm{M}^{\text {pro }}$ will be freely available. The available amounts of inhibitors are limited.

\section{SUPPLEMENTARY MATERIALS}

science.sciencemag.org/cgi/content/full/science.abb3405/DC1

Materials and Methods

Supplementary Text

Scheme S1

Figs. S1 to S10

Tables S1 to S3

References (20-42)

17 February 2020; accepted 18 March 2020

Published online 20 March 2020

10.1126/science.abb3405 


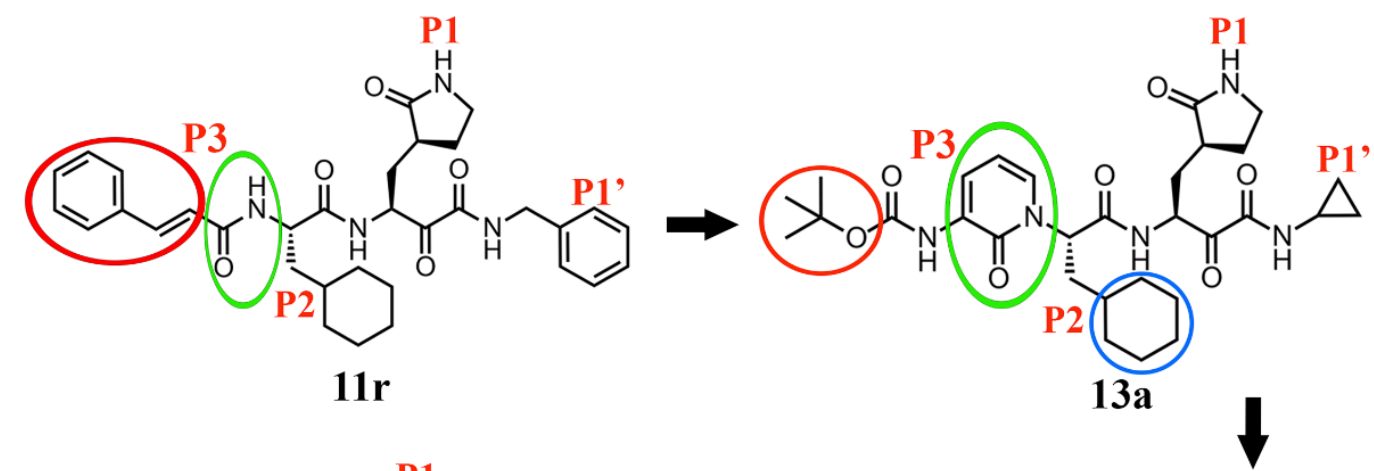

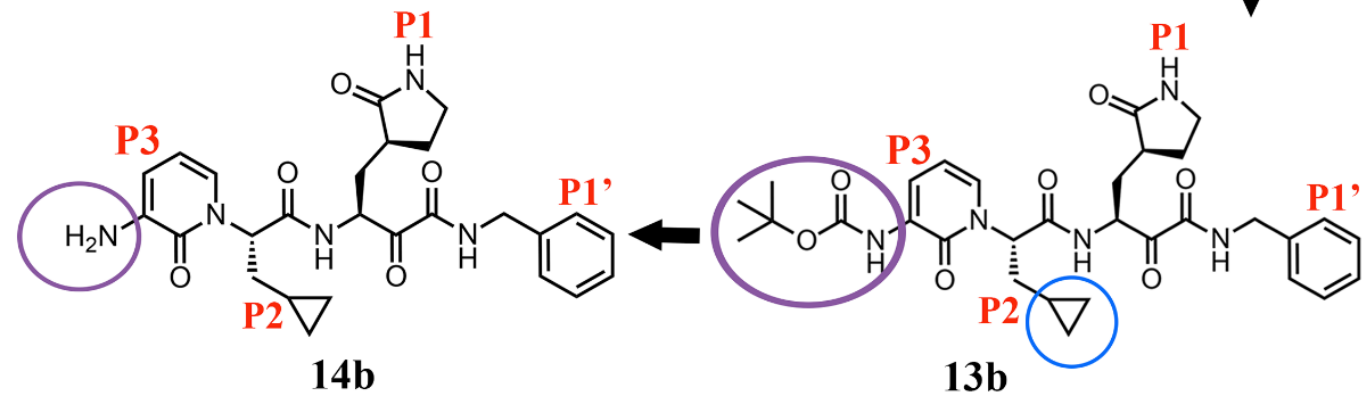

Fig. 1. Chemical structures of $\alpha$-ketoamide inhibitors $11 r, 13 a, 13 b$, and 14b. Colored circles highlight the modifications from one development step to the next (see text).
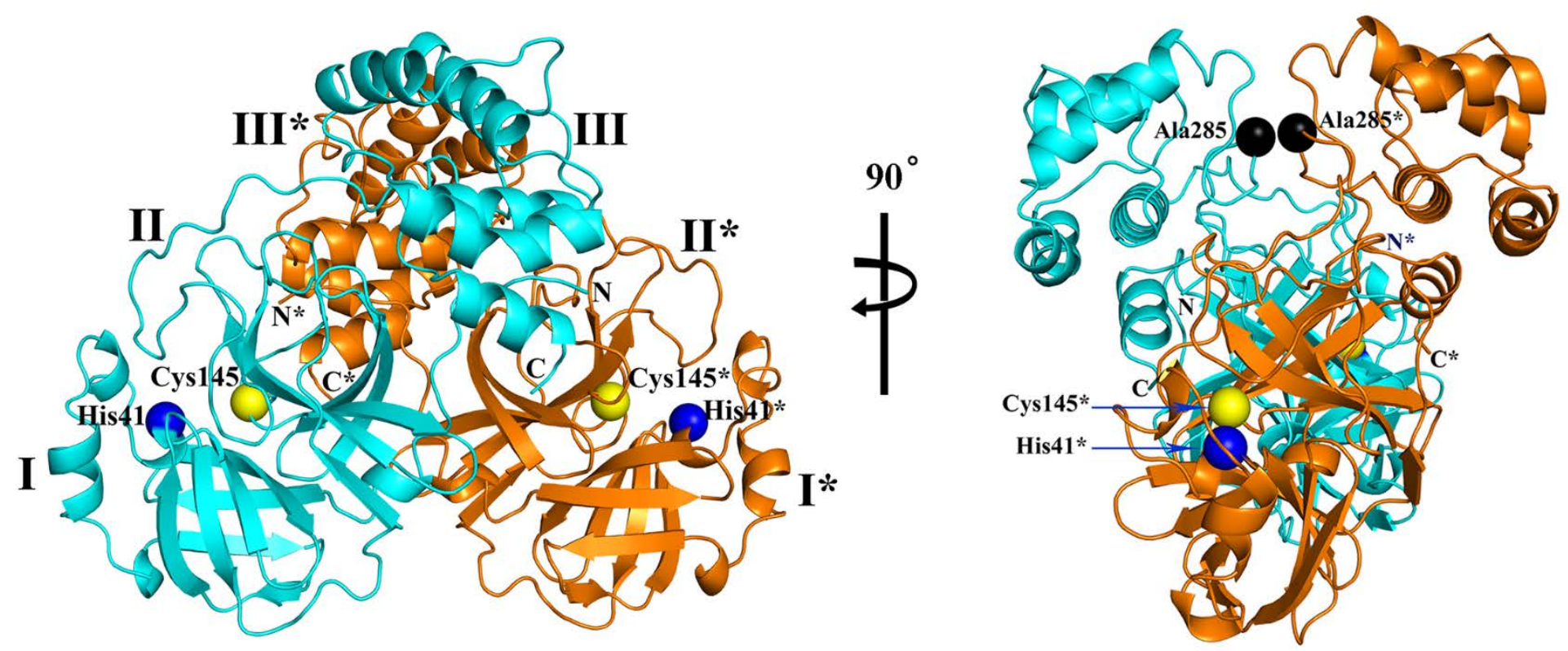

Fig. 2. Three-dimensional structure of SARS-CoV-2 $\mathrm{M}^{\text {pro, }}$, in two different views. One protomer of the dimer is shown in light blue, the other one in orange. Domains are labeled by Roman numbers. Amino-acid residues of the catalytic site are indicated as yellow and blue spheres, for $\mathrm{Cys}^{145}$ and $\mathrm{His}^{41}$, respectively. (An asterisk marks a residue from protomer $\mathrm{B}$ (orange)). Black spheres indicate the positions of Ala ${ }^{285}$ of each of the two domains III (see text). Chain termini are labeled $\mathrm{N}$ and $\mathrm{C}$ for molecule $\mathrm{A}$ (light blue) and $\mathrm{N}^{*}$ and $\mathrm{C}^{*}$ for molecule $\mathrm{B}$ (orange). 


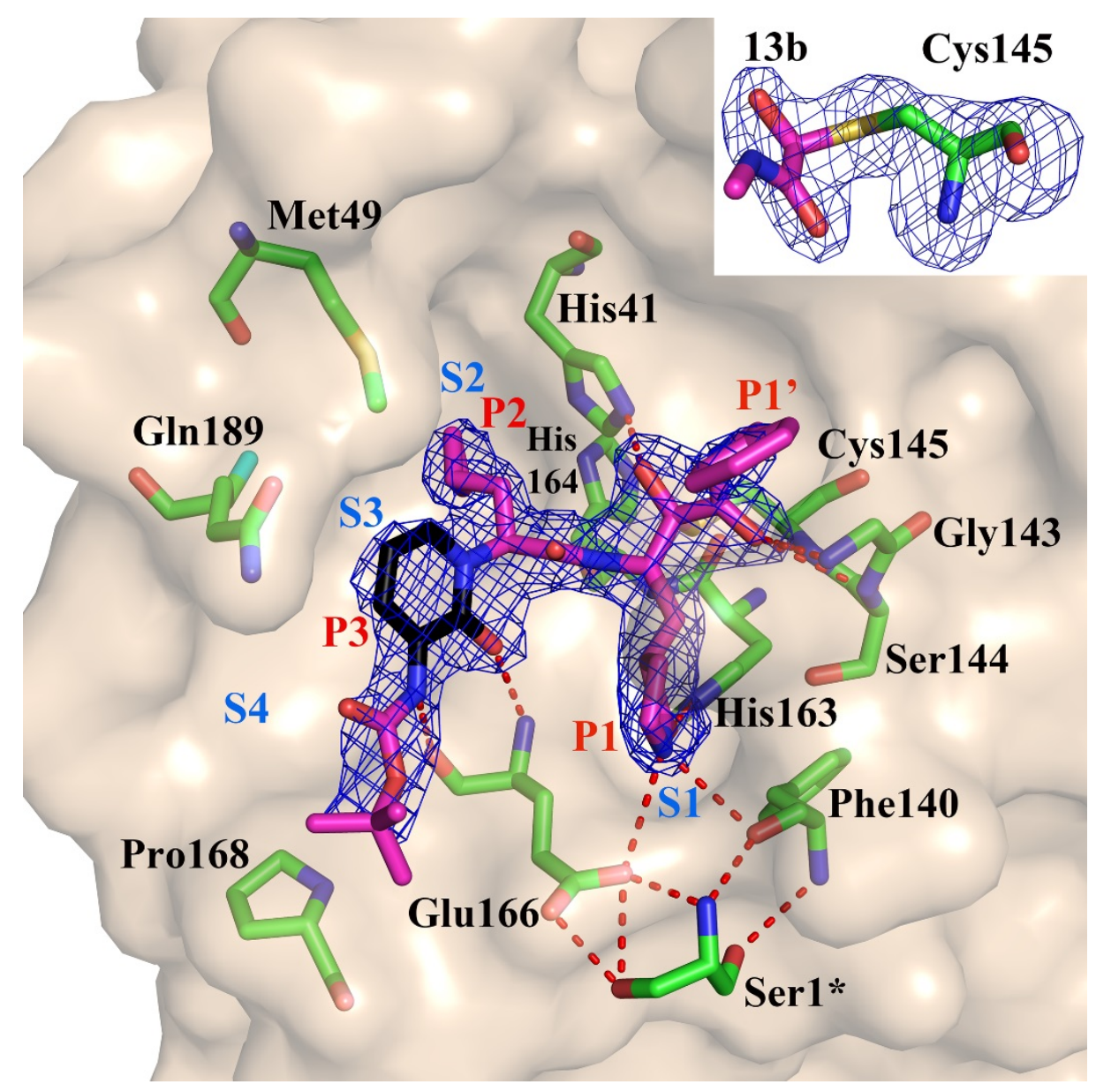

Fig. 3. Compound $13 \mathrm{~b}$ in the substrate-binding cleft located between domains I and II of the $\mathrm{M}^{\text {pro }}$, in the monoclinic crystal form (space group $C 2$ ). $F_{o}-F_{c}$ density is shown for the inhibitor (contouring level: $3 \sigma$ ). Carbon atoms of the inhibitor are magenta, except in the pyridone ring, which is black; oxygen atoms are red, nitrogens blue, and sulfur yellow. Light-blue symbols S1, S2, S3, S4 indicate the canonical binding pockets for moieties P1, P2, P3, P4 (red symbols) of the peptidomimetic inhibitor. Hydrogen bonds are indicated by dashed red lines. Note the interaction between the N-terminal residue of chain B, Ser ${ }^{1 *}$, and Glu ${ }^{166}$ of chain A, which is essential for keeping the S1 pocket in the right shape and the enzyme in the active conformation. Inset: Thiohemiketal formed by the nucleophilic attack of the catalytic cysteine onto the $\alpha$ carbon of the inhibitor in its $F_{0}-F_{c}$ density (contoured at $3 \sigma$ ). The stereochemistry of the $\alpha$-carbon is $S$. See fig. S8 for more details. 

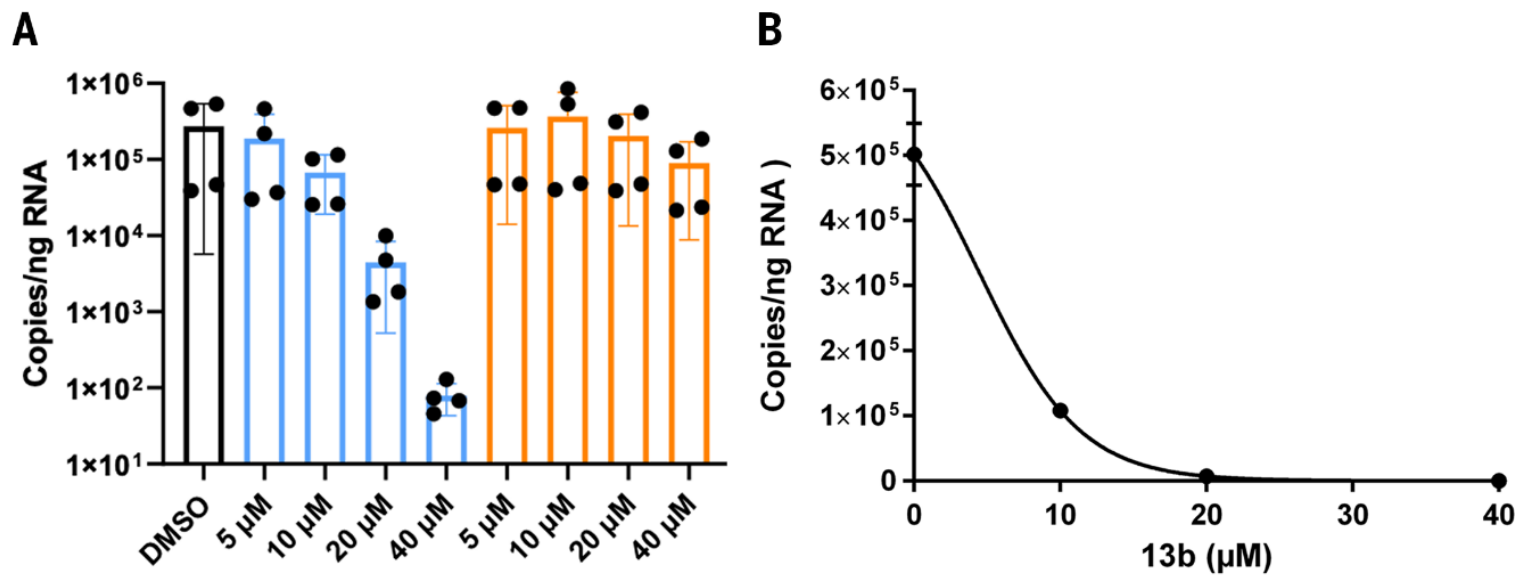

$13 \mathrm{~b} \quad 14 \mathrm{~b}$

Fig. 4. Compound 13b inhibits SARS-CoV-2 replication in human Calu3 lung cells. (A) Calu-3 cells were infected with SARS-CoV-2 using an MOI of 0.05 and stimulated with DMSO (black bar) or different amounts $(5,10,20$, or $40 \mu \mathrm{M})$ of $13 \mathrm{~b}$ (blue bars) or $14 \mathrm{~b}$ (orange bars) and analyzed at 24 hours p.i.. In (A), total RNA was isolated from cell lysates and viral RNA content was analyzed by qPCR. (B) For the estimation of the $\mathrm{EC}_{50}$ value of compound $13 \mathrm{~b}$ against SARS-CoV-2, a dose-response curve was prepared (GraphPad). (A) represents means \pm SD of two biological experiments with two technical replicates each. 